\title{
BMJ Open How well are sepsis and a sense of urgency documented throughout the acute care chain in the Netherlands? A prospective, observational study
}

\author{
Gideon Latten (D) , ${ }^{1}$ Kirsten Hensgens, ${ }^{1}$ Eefje G P M de Bont, ${ }^{2}$ \\ Jean W M Muris (D) , ${ }^{2}$ Jochen W L Cals, ${ }^{2}$ Patricia Stassen (i) ${ }^{3}$
}

To cite: Latten $\mathrm{G}$, Hensgens $\mathrm{K}$, de Bont EGPM, et al. How well are sepsis and a sense of urgency documented throughout the acute care chain in the Netherlands? A prospective, observational study. BMJ Open 2020;10:e036276. doi:10.1136/ bmjopen-2019-036276

- Prepublication history and additional material for this paper are available online. To view these files, please visit the journal online (http://dx.doi. org/10.1136/bmjopen-2019036276).

Received 10 December 2019 Revised 17 March 2020 Accepted 26 May 2020

Check for updates

(c) Author(s) (or their employer(s)) 2020. Re-use permitted under CC BY-NC. No commercial re-use. See rights and permissions. Published by BMJ.

${ }^{1}$ Emergency Department, Zuyderland Medical Centre Heerlen, Heerlen, The Netherlands

${ }^{2}$ Family Medicine, Maastricht University, Research Institute CAPHRI, Maastricht, Limburg, The Netherlands

${ }^{3}$ Internal Medicine, MUMC,

Maastricht, The Netherlands

Correspondence to

Dr Gideon Latten;

g.latten@zuyderland.nl

\section{ABSTRACT}

Objective To investigate the documentation of sepsis and a sense of urgency throughout the acute care chain.

Design Prospective cohort study.

Setting Emergency department (ED) in a large district hospital in Heerlen, The Netherlands.

Participants Participants included patients $\geq 18$ years with suspected sepsis who visited the ED during outof-hours between September 2017 and January 2018 $(n=339)$ and had been referred by a general practitioner and/or transported by ambulance. We defined suspected sepsis as suspected or proven infection and the presence of $\geq 2$ quick Sepsis-related Organ Failure Assessment and/ or $\geq 2$ Systemic Inflammatory Response Syndrome criteria. Outcome measures We analysed how often sepsis and a sense of urgency were documented in the prehospital and ED medical records. A sense of urgency was considered documented when a medical record suggested the need of immediate assessment by a physician in the ED. We described documentation patterns throughout the acute care chain and investigated whether documentation of sepsis or a sense of urgency is associated with adverse outcomes (intensive care admission/30-day all-cause mortality).

Results Sepsis was documented in $16.8 \%$ of medical records and a sense of urgency in $22.4 \%$. In $4.1 \%$ and $7.7 \%$, respectively, sepsis and a sense of urgency were documented by all involved professionals. In patients with an adverse outcome, sepsis was documented more often in the ED than in patients without an adverse outcome (47.9\% vs $13.7 \%, p<0.001)$.

Conclusions Our study shows that in prehospital and ED medical records, sepsis and a sense of urgency are documented in one out of five patients. In only 1 out of 20 patients sepsis or a sense of urgency is documented by all involved professionals. It is possible that poor documentation causes harm, due to delayed diagnosis or treatment. Hence, it could be important to raise awareness among professionals regarding the importance of their documentation.

\section{INTRODUCTION}

Sepsis is a potentially lethal syndrome, and its incidence is still rising. ${ }^{1}$ Prior to emergency department (ED) arrival, many patients
Strengths and limitations of this study

- This is the first study investigating out-of-hours documentation of 'sepsis' and the presence of a sense of urgency in acute care chain medical records.

- This study had only $2.3 \%$ missing medical records.

- We investigated written documentation without taking verbal handovers into account.

- We defined suspected sepsis based on vital parameters in the emergency department; these parameters could have been different on assessment in the prehospital setting.

with sepsis have one or more contacts with a general practitioner (GP) and/or emergency medical services (EMS). ${ }^{2}$ As early recognition and treatment can improve outcome, prehospital professionals are key players in the recognition and management of patients with sepsis. ${ }^{45}$ This is especially true during out-of-office hours, when patients are assessed by GPs on duty, who most often do not know the patient and his or her history and comorbidities.

To date, it is not exactly known how well sepsis is recognised and documented by healthcare professionals working in acute care during out-of-office hours. A few studies, mainly focusing on EMS, have found documentation rates between $10 \%$ and $40 \%^{367}$ In addition, the urgency with which patients need to be treated is often not mentioned. ${ }^{8}$ Possible explanations for these low rates include the absence of a gold standard for sepsis and a lack of awareness that adequate documentation of both the diagnosis and the urgency of sepsis is important.

In other time-dependent conditions such as stroke or acute coronary syndrome (ACS), early recognition and interventions to increase awareness among health professionals on the importance of timely diagnosis and treatment 
have been shown to improve survival substantially. ${ }^{9-11}$ Due to improved awareness and specific care systems, patients with a possible stroke or ACS immediately raise a sense of urgency. Taking the similar mortality rates of stroke, ACS and sepsis into account, one could assume that documenting sepsis when referring or transporting a patient to the hospital will also directly generate a sense of urgency. It is likely, however, that physicians in (crowded) EDs will prioritise patients, even across those meeting sepsis criteria, as not all patients with sepsis are equally ill. To our knowledge, no studies have investigated the documentation of a sense of urgency in acute care chain medical records, in relation to documentation of 'sepsis'.

In this prospective, observational study of ED patients with suspected sepsis, we investigated (1) how often the suspicion of sepsis is documented throughout the acute care chain during out-of-hours, (2) how often a sense of urgency is documented throughout the acute care chain, and (3) the association between documentation of sepsis and the documentation of a sense of urgency. Fourth, we investigated the association of documentation of sepsis or a sense of urgency with adverse outcomes (intensive care admission and/or 30-day mortality).

\section{METHODS}

\section{Design and setting}

In this study, ED patients with suspected sepsis were enrolled prospectively, after which their medical records (ie, GP referral letters, EMS charts and ED charts) were reviewed retrospectively. We included patients at the ED in a large district hospital providing care to a region with 260000 inhabitants (Zuyderland Hospital Heerlen, The Netherlands), during out-of-hours (Monday through Friday from 17:00 to 08:00, and during weekends) between 2 September 2017 and 6 January 2018. The ED in Heerlen provides general and specialised acute medical care to the region, including patients referred by GPs and EMS. Less than 3\% of ED patients are walk-ins (ie, unreferred, without involvement of GP and/or EMS), which is a common percentage in the Netherlands. ${ }^{12}$ We focused on patients during out-of-hours as the co-located GP cooperative provides a digital referral for nearly $100 \%$ of patients.

Out-of-hours primary care in the Netherlands is organised in large-scaled GP cooperatives, which serve as the first step in emergency care. At these cooperatives, 50-150 GPs take rotating shifts during out-of-hours. For out-of-hours medical complaints, patients have to contact their nearby GP cooperative by telephone. If physical assessment by a GP is deemed necessary based on the telephone triage system (Netherlands Triage Standard, NTS), they can either get a GP appointment at the cooperative's facility or be scheduled for a home visit by a GP. ${ }^{13}$ GPs have a gate-keeping function in the Netherlands, which means that most patients are seen by a GP before they are referred to an ED. The participating cooperative's location in this study adjacent to the ED is customary in the Netherlands. ${ }^{14}$

For life-threatening complaints, patients are supposed to call the national emergency telephone number (112). If a patient inadvertently calls the GP cooperative and lifethreatening complaints are suspected, immediate assessment by EMS is ordered. EMS nurses in the Netherlands are highly trained, usually with experience in acute and/ or intensive care. They treat and, if necessary, transport the patient to the ED. Similar to the GP cooperatives' triage, EMS dispatch codes are assigned by the ambulance dispatch centre, using NTS. ${ }^{13} \mathrm{~A} 1$ is the most urgent category, indicated for life-threatening situations. A2 is urgent but not life-threatening, and B is for non-urgent conditions.

When a GP refers a patient to the ED, he/she informs the receiving physician-usually a senior staff memberby telephone, and writes a (digital) referral letter from the patient's medical record, which includes the reason for referral, vital parameters, and relevant comorbidities and medication. This letter is immediately available for the treating physician in the ED, but not always for the EMS. They rely on a summary of information, supplied by the EMS dispatch centre and the GP on site. In our ED, triage levels are determined using the Dutch version of the Manchester Triage System. ${ }^{15-17}$

We used the Strengthening the Reporting of Observational Studies in Epidemiology guidelines for reporting this observational study. ${ }^{18}$

\section{Patients}

All patients $\geq 18$ years old with suspected sepsis who visited the ED during out-of-hours and had been referred by a GP and/or transported by EMS were included. We defined suspected sepsis as suspected or proven infection and the presence of $\geq 2$ quick Sepsis-related Organ Failure Assessment (qSOFA) and/or $\geq 2$ Systemic Inflammatory Response Syndrome (SIRS) criteria, based on the vital parameters and laboratory results measured in the ED. ${ }^{19}$ We included patients who had been referred by a GP and/or transported by EMS. We used qSOFA, as it is considered a risk stratification tool for adverse outcomes in patients with an infection. ${ }^{1}$ However, the sensitivity of qSOFA has been found to be low when used as a screening tool for sepsis. ${ }^{2021}$ We therefore included patients with $\geq 2$ SIRS criteria as well.

Patients were excluded if they were walk-ins or had been referred by a different physician than a GP (eg, elderly care physician), in case of an ED diagnosis of sterile inflammation (eg, pancreatitis, pericarditis), and when a patient visited the ED for a second time during the inclusion period. The screening process for eligibility was conducted by two independent researchers, according to an established protocol. Follow-up data (30 days after hospital discharge) were obtained by retrieval of hospital records or by telephone contact with the patient's GP. 


\section{Data collection}

Patient data were collected using a case report form, comprising data from the patient's medical records. We retrieved general patient information, as well as information regarding the patient's referral pathway (GP, EMS, ED, hospital).

\section{Definitions}

Comorbidities were quantified using the Charlson Comorbidity Index. ${ }^{22}$ For the calculation of SIRS and qSOFA, the most abnormal vital parameters (blood pressure, heart rate, respiratory rate, oxygen saturation, Glasgow Coma Scale, temperature) in the ED were used. Adverse outcomes were defined as intensive care unit (ICU) admission, 30-day all-cause mortality or both.

We retrieved the documentation of the word 'sepsis' (literally) and the documentation of a sense of urgency. The documentation of a sense of urgency (yes/no) was based on the complete text in each medical record (ie, not on the documentation of 'sepsis' alone). This was judged by an assessment panel of three acute healthcare professionals (a GP, an acute internist and an ED consultant) who independently assessed patients' medical records. The medical records were anonymised and randomly shuffled in such a way that the assessors could not match (GP, EMS, ED) records of a patient in the acute care chain. In addition, the assessors were blinded to the clinical outcomes of patients after the ED visit. A record was considered to have documented a sense of urgency when it suggested that the patient was in need of immediate assessment by a physician in the ED. No specific cues were provided to the panel, as their judgement regarding the sense of urgency reflects daily practice. In case of disagreement, the panel discussed the case face-to-face, aiming to reach consensus. In case of persistent disagreement, the majority rule was applied.

\section{Analyses}

Descriptive analysis was performed in order to provide insight into the baseline patient characteristics and referral pathways. We analysed how often sepsis and a sense of urgency were documented in the medical records. We described the patterns of documentation of both sepsis and a sense of urgency throughout the acute care chain. In order to test the hypothesis that 'sepsis' is documented more often in patients with a documented sense of urgency, we analysed the association and agreement between these two. Finally, we investigated whether there was an association between the documentation of sepsis or a sense of urgency and adverse outcomes (ICU admission and/or 30-day mortality).

\section{Statistical methods}

All statistical analyses were performed using IBM SPSS V.25 statistical software. Continuous data were reported as mean with SD and compared using Student's t-test, or as median with IQR, and compared using the Mann-Whitney $\mathrm{U}$ test. We reported categorical data as absolute numbers and as valid percentages (to correct for missing data); these were compared using $\chi^{2}$ or Fisher's exact tests. A p value $<0.05$ was considered statistically significant.

Regarding the documentation of a sense of urgency, we calculated the number of medical records in which there was immediate agreement between the three professionals and the proportion in which there was agreement after face-to-face discussion. Fleiss kappa values were calculated to determine the level of agreement.

To investigate the association between the documentation of sepsis and a sense of urgency, we calculated OR with $95 \%$ CI. We reported kappa values for the agreement between the documentation of sepsis and a sense of urgency. Kappa values of 0.6-0.8 represent moderate, values of $0.8-0.9$ strong, and values $>0.9$ almost perfect agreement. $^{23}$

For this study, we calculated the minimum sample size to be able to detect a difference in sepsis documentation of $25 \%$ between patients with and without an adverse outcome. With an estimated adverse event rate of $12.5 \%$, and documentation of sepsis at least once in $50 \%$ of patients with and in $25 \%$ of patients without an adverse outcome, we required 35 patients with an adverse outcome and 280 without one, resulting in a target sample size of 315 patients.

\section{RESULTS}

\section{Patients and referral pathways}

We recruited 339 patients with (suspected/proven) infection and $\geq 2$ SIRS and/or qSOFA criteria who visited the ED during out-of-hours (table 1), with a median age of 68 years. Of all patients, $269(79 \%)$ were referred by the GP and $193(57 \%)$ were assessed and transported by EMS. The included 339 patients had a total of 800 medical records: 268 GP referral letters, 193 EMS charts and 339 ED charts. Of these, 16 GP referral letters and 2 EMS charts could not be retrieved, leaving 782 complete medical records available for analyses (online supplementary file - database).

\section{Documentation of sepsis}

Sepsis was literally documented in 131 (16.8\%) of the 782 records (figure 1). GP referral letters contained the word 'sepsis' in 35 (13.9\%), EMS charts in 33 (12.3\%) and ED charts in $63(18.6 \%)$ cases. In $92(27.1 \%)$ patients, sepsis was documented by at least one healthcare professional in the acute care chain.

The different patterns of sepsis documentation in the acute care chain are illustrated in figure 2. In 14 (4.1\%) patients, all involved professionals documented sepsis, while in $247(72.9 \%)$ none mentioned it. In all other cases $(n=78,23.0 \%)$, sepsis was documented at least once, but not by all professionals.

\section{Sense of urgency}

The assessment panel agreed on the sense of urgency being present/absent in $515(65.9 \%)$ cases (online 


\begin{tabular}{|c|c|}
\hline \multicolumn{2}{|l|}{ General } \\
\hline Age (years) & $68(53-78)$ \\
\hline Male & $151(44.5)$ \\
\hline Comorbidities (CCl) & $1(0-2)$ \\
\hline \multicolumn{2}{|l|}{ Referral pathway } \\
\hline Referred by GP & $268(79.1)$ \\
\hline Transport by EMS & $193(56.9)$ \\
\hline \multicolumn{2}{|c|}{ Referral pathway, contact with: } \\
\hline $\mathrm{GP}+\mathrm{EMS}+\mathrm{ED}$ & $122(35.6)$ \\
\hline $\mathrm{GP}+\mathrm{ED}$ & $146(43.1)$ \\
\hline EMS+ED & $71(20.9)$ \\
\hline \multicolumn{2}{|c|}{ EMS dispatch code $(n=185 \dagger)$} \\
\hline A1 & 77 (41.6) \\
\hline A2 & $83(44.9)$ \\
\hline B & $25(13.5)$ \\
\hline \multicolumn{2}{|l|}{ ED } \\
\hline qSOFA $\geq 2$ & 47 (13.9) \\
\hline$S I R S \geq 2$ & $336(99.1)$ \\
\hline
\end{tabular}

*Values are n (\%) for ordinal variables and median (IQR) for continuous variables.

†Eight missing.

$\mathrm{CCl}$, Charlson Comorbidity Index; ED, emergency department; EMS, emergency medical services; GP, general practitioner; qSOFA, quick Sepsis-related Organ Failure Assessment; SIRS, Systemic Inflammatory Response Syndrome.

supplementary table 1). Face-to-face discussion was necessary for $267(34.1 \%)$ medical records. After discussion, agreement was reached for $90.5 \%$ of records. Fleiss kappa values varied between 0.36 and 0.43 before discussion, and between 0.71 and 0.91 after discussion.

In the end, the panel agreed that in 175 (22.4\%) medical records, a sense of urgency was documented (figure 1). GPs documented a sense of urgency in $38(31.0 \%)$, EMS in $46(24.1 \%)$ and ED physicians in $51(15.0 \%)$ cases. In $123(36.3 \%)$ patients, a sense of urgency was documented in at least one record within the acute care chain.

Figure 2 shows the different patterns in the acute care chain of the documented sense of urgency in medical records. In $26(7.7 \%)$ patients, all medical records contained a sense of urgency, and in $216(63.7 \%)$ none did.

\section{Association and agreement between the documentation of 'sepsis' and a sense of urgency}

In $71(9.1 \%)$ medical records, 'sepsis' as well as a sense of urgency were documented (table 2). In 547 (69.9\%) records, neither was documented.

We found a significant association between the documentation of sepsis and the documentation of a sense of urgency. ORs varied between 2.9 for EMS charts and 16.6 for GP referral letters. Kappa values for the agreement between the documentation of 'sepsis' and a sense of urgency were 0.40 for GP referral letters, 0.19 for EMS charts and 0.39 for ED charts.

\section{Comparison between patients with and without an adverse outcome}

In total, $48(14.2 \%)$ patients experienced an adverse outcome. ICU admission was necessary for $36(10.6 \%)$ patients and $16(4.7 \%)$ died within 30 days (table 3 ). In patients with an adverse outcome, 'sepsis' was more often documented at least once in the acute care chain $(54.2 \%$ vs $22.7 \%, \mathrm{p}<0.001)$. We found 'sepsis' documentation
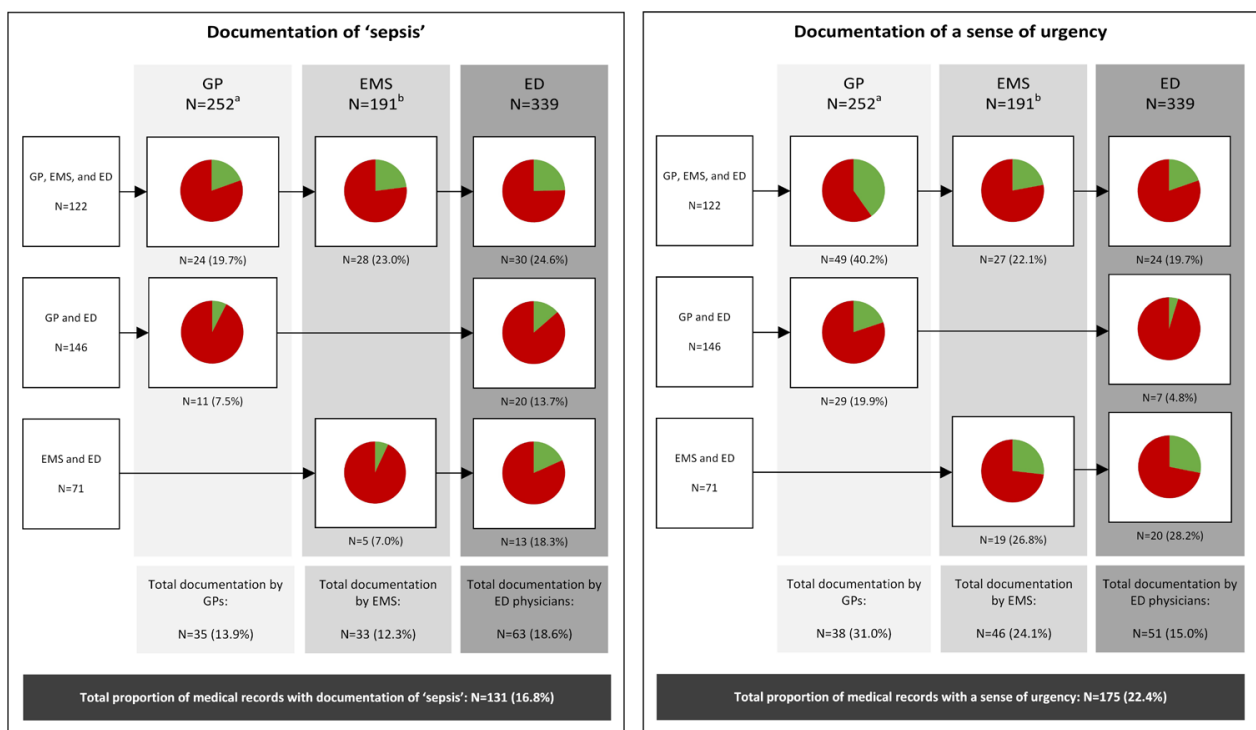

Figure 1 Documentation of 'sepsis' and a sense of urgency in medical records. Values are $\mathrm{n}(\%) ;{ }^{\mathrm{a}} 16 \mathrm{missing}$, ${ }^{\mathrm{b}} 2 \mathrm{missing}$. Left figure-documentation of 'sepsis': green: 'sepsis' documented; red: 'sepsis' not documented. Right figure-documentation of a sense of urgency: green: sense of urgency documented; red: no sense of urgency documented. ED, emergency department; EMS, emergency medical services; GP, general practitioner. 

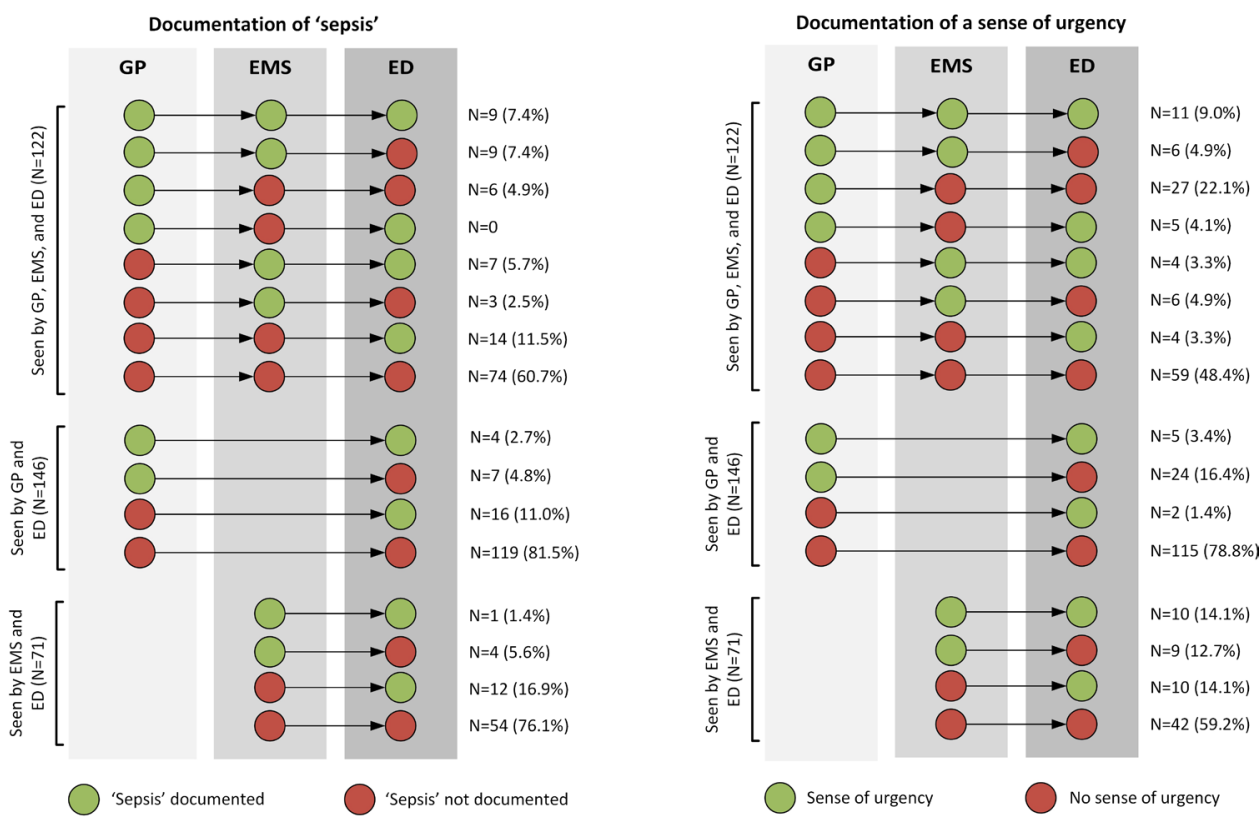

Figure 2 Patterns of 'sepsis' documentation and a sense of urgency. ED, emergency department; EMS, emergency medical services; GP, general practitioner.

more often in ED records of those with than in those without an adverse outcome $(47.9 \%$ vs $13.7 \%$, $\mathrm{p}<0.001)$, but this pattern was not found in GP and EMS medical records.

Throughout the acute care chain, a sense of urgency was documented more often in patients with than in patients without an adverse outcome (table 3 ).

\section{DISCUSSION}

\section{Main findings}

In this prospective observational study, we found that in ED patients with suspected sepsis, the word 'sepsis' was literally documented in $16.8 \%$ of all prehospital and ED medical records. In only $4.1 \%$ of patients 'sepsis' was documented by all professionals involved in the acute care chain. We found similar results for the documentation of a sense of urgency. Despite a significant association between the documentation of 'sepsis' and of a sense of urgency, agreement between these two was low (kappa
0.19-0.40). In patients with an adverse outcome, sepsis and a sense of urgency were documented more often than in patients without an adverse outcome.

\section{Comparison with existing literature}

In our study, 'sepsis' was documented at least once in the acute care chain in $27.1 \%$ of patients. Previous studies found similar results, with prehospital documentation rates between $10 \%$ and $40 \% .^{367}$ A likely contributor to poor recognition is the absence of a gold standard test for sepsis. Furthermore, loss of information and semantics (eg, documenting pneumonia instead of pneumosepsis) are possible explanations. It is also possible that the term 'sepsis' does not cover the severity of the disease or the professional's sense of urgency.

An important finding in our study is the fact that 'sepsis' was documented by all professionals in only $4.1 \%$ of patients. Poor handover strategies, disagreement between professionals and varying vital parameters over time are possible explanations. In our region, GPs and

Table 2 Association and agreement between the documentation of 'sepsis' and a sense of urgency

\begin{tabular}{|c|c|c|c|c|c|c|c|}
\hline & & & \multicolumn{2}{|c|}{$\begin{array}{l}\text { Sense of urgency } \\
\text { documented }\end{array}$} & \multirow[b]{2}{*}{ OR $(95 \% \mathrm{Cl})$} & \multirow[b]{2}{*}{$P$ value } & \multirow[b]{2}{*}{ Kappa } \\
\hline & & & Yes & No & & & \\
\hline \multirow{2}{*}{$\begin{array}{l}\text { GP referral } \\
\text { letters }\end{array}$} & \multirow{2}{*}{$\begin{array}{l}\text { 'Sepsis' } \\
\text { documented }\end{array}$} & Yes & 29 & 6 & 16.6 (7 to 42$)$ & $<0.001$ & 0.4 \\
\hline & & No & 49 & 168 & & & \\
\hline \multirow[t]{2}{*}{ EMS charts } & \multirow{2}{*}{$\begin{array}{l}\text { 'Sepsis' } \\
\text { documented }\end{array}$} & Yes & 14 & 19 & 2.9 (1 to 6$)$ & 0.007 & 0.19 \\
\hline & & No & 32 & 126 & & & \\
\hline \multirow[t]{2}{*}{ ED charts } & \multirow{2}{*}{$\begin{array}{l}\text { 'Sepsis' } \\
\text { documented }\end{array}$} & Yes & 28 & 35 & 8.8 (5 to 17$)$ & $<0.001$ & 0.39 \\
\hline & & No & 23 & 253 & & & \\
\hline
\end{tabular}

ED, emergency department; EMS, emergency medical services; GP, general practitioner. 
Table 3 Comparison between patients with and without an adverse outcome*

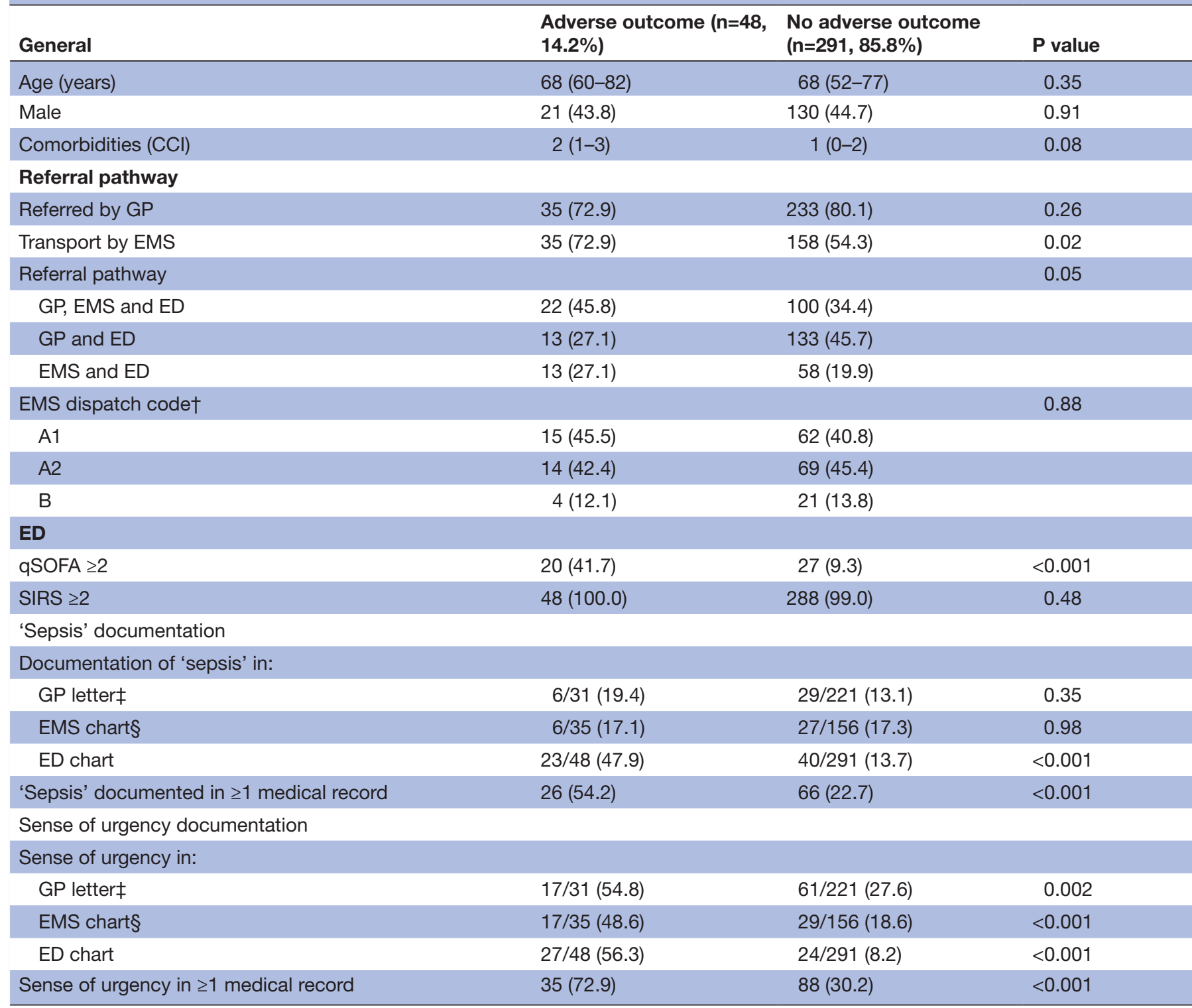

*Values are $\mathrm{n}(\%)$ for ordinal variables and median (IQR) for continuous variables, unless otherwise specified. $\dagger \mathrm{n}=185$ (8 missing). $\ddagger 16$ missing.

$\S 2$ missing.

$\mathrm{CCI}$, Charlson Comorbidity Index; ED, emergency department; EMS, emergency medical services; GP, general practitioner; qSOFA, quick Sepsis-related Organ Failure Assessment; SIRS, Systemic Inflammatory Response Syndrome.

EMS use digital handovers. These are transmitted directly to the ED (and are thus immediately available), but EMS personnel cannot see the complete GP's handover. Therefore, they rely on a summary of information, supplied by the EMS dispatch centre, supplemented by an analogue letter supplied by the GP. Verbal handover may reduce loss of information, but an adequate written handover is still necessary, as previous research has shown that a substantial amount of information is lost in verbal handovers. ${ }^{824}$

In addition to documentation of 'sepsis', we were, to our knowledge, the first to also investigate the documentation of a sense of urgency in medical records. In only $7.7 \%$ of patients all medical records of the same patient documented a sense of urgency. When we compared the documentation of 'sepsis' with the documentation of a sense of urgency in the medical records, we found a significant association between these two (OR 6.2). However, agreement was low with kappa values of 0.40 for GP referral letters, 0.19 for EMS charts and 0.39 for ED charts. This may suggest two things. First, mentioning 'sepsis' in a medical record does not automatically generate a sense of urgency. Possibly, professionals use the word 'sepsis' when a patient meets a specific set of criteria (eg, SIRS criteria), even when they do not consider the patient to be severely ill. Second, patients who do not appear severely ill are not 
considered to be 'septic'. Either can be caused by professionals not considering sepsis as the most important differential diagnosis, the lack of a gold standard test and the belief documenting sepsis is not useful. ${ }^{8}$

When comparing patients with and without an adverse outcome, we found that ED charts of patients with an adverse outcome more often contained the word 'sepsis' ( $47.9 \%$ vs $13.7 \%, \mathrm{p}<0.001)$, which is in line with previous studies. ${ }^{25}$ We did not find this difference in prehospital (GP, EMS) documentation, possibly due to the fact that the suspicion of sepsis can be made more definite once diagnostics-leucocytes or partial pressure of carbon dioxide, both SIRS criteria-are performed in the ED. Noteworthy is that we found that GP and EMS medical records of patients with an adverse outcome significantly more often documented a sense of urgency than those without an adverse outcome (GP 54.8\% vs $27.6 \%$; EMS $56.3 \%$ vs $8.2 \%$ ). This suggests that these professionals acknowledged the urgency with which these patients needed to be treated, but that they did not document sepsis or did not consider this as a differential diagnosis. Half of the medical records of those with an adverse outcome, however, still did not contain a sense of urgency. This suggests there is still room for improvement.

\section{Strengths and limitations}

Our study has two major strengths. First, to our knowledge, this is the first study comparing out-of-hours documentation of 'sepsis' with the presence of a sense of urgency in acute care chain medical records. Second, our study had only $2.3 \%$ missing medical records. Our results therefore reflect a best-case scenario. It is likely that in daily practice, there is more missing information due to lost records, causing poorer results than found in our study. A limitation could be that we investigated written documentation without taking verbal handovers into account. It is possible that GPs mentioned sepsis over the phone, but did not document it, especially in patients requiring urgent care. Prehospital medical records, however, should be an adequate representation of the information that needs to be communicated, especially since there can be loss of information within the hospital as well. Second, we defined 'sepsis' based on vital parameters in the ED. It is possible that prior to ED arrival, patients did not meet sepsis criteria, or that laboratory results-available only in the ED-made the diagnosis of sepsis more likely. ${ }^{7}$ Finally, the subjectivity in judgement of handovers by three healthcare professionals may be a limitation. After discussion, there was still disagreement in $9.8 \%$ of the records by the assessment panel, showing how difficult it is to adequately judge documented information on this topic.

\section{CONCLUSION AND IMPLICATIONS}

In conclusion, our study shows that in prehospital and ED medical records, sepsis and a sense of urgency are documented in one out of five patients. In only 1 out of
20 patients sepsis or a sense of urgency is documented by all involved professionals in the acute care chain. It is possible that poor documentation causes harm, due to delayed diagnosis or treatment. Hence, it could be important to raise awareness among healthcare professionals regarding the importance of their documentation. Our study provides a basis for future, preferably qualitative, research investigating why 'sepsis' and a sense of urgency are documented so infrequently in handovers; is it uncertainty about the diagnosis, lack of knowledge or disagreement regarding the severity of illness? If it is found that professionals are hesitant to mention 'sepsis', since they are not certain of the diagnosis, this should be a target for future interventions. Similar to myocardial infarction and stroke, patients are sent to the ED with a probability diagnosis, and once a prehospital professional suspects sepsis this suspicion should be carried on throughout the acute care chain.

Twitter Gideon Latten @gideonlatten, Eefje G P M de Bont @eefje_de_bont and Jean W M Muris @MurisJean

Contributors PS and GL were involved in the conception and design of the study. $\mathrm{KH}$ included the patients. GL organised the data, had full access to the data and wrote the first draft. EGPMB, GL and PS comprised the assessment panel. KH, EGPMB, JWMM, JWLC and PS revised the manuscript and approved the final version for submission.

Funding The authors have not declared a specific grant for this research from any funding agency in the public, commercial or not-for-profit sectors.

Competing interests None declared.

Patient and public involvement Patients and/or the public were not involved in the design, or conduct, or reporting, or dissemination plans of this research.

Patient consent for publication Not required.

Ethics approval The study was reviewed and approved by the medical ethics committee Zuyderland-Zuyd (METC-Z nr. 17-N-120).

Provenance and peer review Not commissioned; externally peer reviewed.

Data availability statement All data relevant to the study are included in the article or uploaded as supplementary information.

Open access This is an open access article distributed in accordance with the Creative Commons Attribution Non Commercial (CC BY-NC 4.0) license, which permits others to distribute, remix, adapt, build upon this work non-commercially, and license their derivative works on different terms, provided the original work is properly cited, appropriate credit is given, any changes made indicated, and the use is non-commercial. See: http://creativecommons.org/licenses/by-nc/4.0/.

ORCID iDs

Gideon Latten http://orcid.org/0000-0002-4110-5242

Jean W M Muris http://orcid.org/0000-0002-8780-476X

Patricia Stassen http://orcid.org/0000-0003-0864-1542

\section{REFERENCES}

1 Singer M, Deutschman CS, Seymour CW, et al. The third International consensus definitions for sepsis and septic shock (Sepsis-3). JAMA 2016;315:801-10.

2 Latten GHP, Claassen L, Jonk M, et al. Characteristics of the prehospital phase of adult emergency department patients with an infection: a prospective pilot study. PLoS One 2019;14:e0212181.

3 Groenewoudt M, Roest AA, Leijten FMM, et al. Septic patients arriving with emergency medical services: a seriously ill population. Eur J Emerg Med 2014;21:330-5.

4 Alam N, Oskam E, Stassen PM, et al. Prehospital antibiotics in the ambulance for sepsis: a multicentre, open label, randomised trial. Lancet Respir Med 2018;6:40-50. 
5 Studnek JR, Artho MR, Garner CL, et al. The impact of emergency medical services on the ED care of severe sepsis. Am J Emerg Med 2012;30:51-6.

6 Alam N, Doerga KB, Hussain T, et al. Epidemiology, recognition and documentation of sepsis in the pre-hospital setting and associated clinical outcomes: a prospective multicenter study. Acute Med 2016;15:168-75.

7 Roest AA, Stoffers J, Pijpers E, et al. Ambulance patients with nondocumented sepsis have a high mortality risk: a retrospective study. Eur J Emerg Med 2017;24:36-43.

8 Matthaeus-Kraemer CT, Thomas-Rueddel DO, Schwarzkopf D, et al. Crossing the handover chasm: clinicians' perceptions of barriers to the early detection and timely management of severe sepsis and septic shock. J Crit Care 2016;36:85-91.

9 Abdullah AR, Smith EE, Biddinger PD, et al. Advance hospital notification by EMS in acute stroke is associated with shorter door-to-computed tomography time and increased likelihood of administration of tissue-plasminogen activator. Prehosp Emerg Care 2008;12:426-31.

10 Chenaitia H, Lefevre O, Ho V, et al. Emergency medical service in the stroke chain of survival. Eur J Emerg Med 2013;20:39-44.

11 Moyer P, Ornato JP, Brady WJ, et al. Development of systems of care for ST-elevation myocardial infarction patients: the emergency medical services and emergency department perspective. Circulation 2007;116:e43-8.

12 Gaakeer MI, van den Brand CL, Gips E, et al. [National developments in emergency departments in the Netherlands: numbers and origins of patients in the period from 2012 to 2015]. Ned Tijdschr Geneeskd 2016;160:D970.

13 Veen van M, lerland van Y, Moll H. Scientific research on the Dutch triage standard ("Wetenschappelijk onderzoek Nederlands Triagesysteem"). 2009, 2017.

14 Smits M, Rutten M, Keizer E, et al. The development and performance of after-hours primary care in the Netherlands: a narrative review. Ann Intern Med 2017;166:737-42.
15 Zachariasse JM, Seiger N, Rood PPM, et al. Validity of the Manchester triage system in emergency care: a prospective observational study. PLoS One 2017;12:e0170811.

16 Manchester Triage Group. Triage voor de spoedeisende hulp. Bohn Stafleu van Loghum, 2016.

17 Mackway-Jones K, Marsden J, Windle J. Emergency triage. Wiley Blackwell, 2014.

18 von Elm E, Altman DG, Egger M, et al. The strengthening the reporting of observational studies in epidemiology (STROBE) statement: guidelines for reporting observational studies. Int J Surg 2014;12:1495-9.

19 Bone RC, Sibbald WJ, Sprung CL. The ACCP-SCCM consensus conference on sepsis and organ failure. Chest 1992;101:1481-3.

20 Askim Åsa, Moser F, Gustad LT, et al. Poor performance of quickSOFA (qSOFA) score in predicting severe sepsis and mortality - a prospective study of patients admitted with infection to the emergency department. Scand J Trauma Resusc Emerg Med 2017;25:56.

21 Tusgul S, Carron P-N, Yersin B, et al. Low sensitivity of qSOFA, SIRS criteria and sepsis definition to identify infected patients at risk of complication in the prehospital setting and at the emergency department triage. Scand J Trauma Resusc Emerg Med 2017;25:108.

22 Charlson ME, Pompei P, Ales KL, et al. A new method of classifying prognostic comorbidity in longitudinal studies: development and validation. J Chronic Dis 1987;40:373-83.

$23 \mathrm{McHugh}$ ML. Interrater reliability: the kappa statistic. Biochem Med 2012;22:276-82.

24 Talbot R, Bleetman A. Retention of information by emergency department staff at ambulance handover: do standardised approaches work? Emerg Med J 2007;24:539-42.

25 Stoneking LR, Winkler JP, DeLuca LA, et al. Physician documentation of sepsis syndrome is associated with more aggressive treatment. West J Emerg Med 2015;16:401-7. 